\title{
Physiological and Stroke Parameters to Assess Aerobic Capacity in Swimming
}

\author{
Mariana F.M. Oliveira, Fabrizio Caputo, Ricardo D. Lucas, \\ Benedito S. Denadai, and Camila C. Greco
}

\begin{abstract}
Purpose: To identify the speed corresponding to anaerobic threshold using the D-max method for both blood lactate and biomechanical stroke parameters determined in an incremental swimming test and to compare this information with the speed corresponding to the maximal lactate steady state $\left(\mathrm{S}_{\mathrm{MLSS}}\right)$. Methods: Five male long-distance swimmers and 8 triathletes $(\mathrm{N}=13$; age $23.8 \pm 9.5 \mathrm{y}$, height $1.76 \pm 0.1 \mathrm{~m}$, weight $71.3 \pm 9.8$ $\mathrm{kg}$ ) performed the following protocols: maximal 400 -m test to determine maximal aerobic speed $\left(\mathrm{S}_{400}\right) ; 7 \times$ 200-m incremental test to determine the speed corresponding to the D-max point on the blood lactate $\left(\mathrm{S}_{\mathrm{La}}\right)$, stroke-rate $\left(\mathrm{S}_{\mathrm{SR}}\right)$, stroke-length $\left(\mathrm{S}_{\mathrm{SL}}\right)$, and stroke-index $\left(\mathrm{S}_{\mathrm{SI}}\right)$ responses; and two to four 30-min submaximal tests to determine the $\mathrm{S}_{\mathrm{MLSs}}$. Results: $\mathrm{S}_{\mathrm{LA}}(1.18 \pm 0.08 \mathrm{~m} / \mathrm{s}), \mathrm{S}_{\mathrm{SI}}(1.18 \pm 0.08 \mathrm{~m} / \mathrm{s}), \mathrm{S}_{\mathrm{SR}}(1.17 \pm 0.1 \mathrm{~m} / \mathrm{s})$, and $\mathrm{S}_{\mathrm{SL}}(1.16 \pm 0.09 \mathrm{~m} / \mathrm{s})$ were not significantly different from each other or from $\mathrm{S}_{\mathrm{MLSS}}(1.13 \pm 0.08 \mathrm{~m} / \mathrm{s})$. There were high correlations between $\mathrm{S}_{\mathrm{LA}}, \mathrm{S}_{\mathrm{SI}}, \mathrm{S}_{\mathrm{SR}}, \mathrm{S}_{\mathrm{SL}}$, and $\mathrm{S}_{\mathrm{MLSS}}(r=.91, .89, .85$, and .80 , respectively). The typical errors of estimate for $\mathrm{S}_{\mathrm{LA}}(3.2 \%), \mathrm{S}_{\mathrm{SI}}(3.7 \%), \mathrm{S}_{\mathrm{SR}}(4.1 \%)$, and $\mathrm{S}_{\mathrm{SL}}(4.7 \%)$ suggest good validity of these variables to predict $\mathrm{S}_{\mathrm{MLSS}}$. Furthermore, all physiological and biomechanical variables were moderately to highly correlated with $\mathrm{S}_{400}(r=.73-.95)$. Conclusions: It is possible to obtain a physiological index of aerobic capacity and performance using simple biomechanical measurements during an incremental test without performing blood lactate analyses.
\end{abstract}

Keywords: lactate, maximal lactate steady state, D-max method

The maximal lactate steady state (MLSS), which has received much attention from sport researchers as the "gold standard" in determining aerobic capacity, ${ }^{1}$ is defined as the highest intensity at which lactate production and elimination are in equilibrium. The method Heck et $\mathrm{al}^{2}$ proposed for determining the intensity corresponding to MLSS (MLSS WORKLOAD $_{\text {) requires several constant }}$ submaximal-load tests performed on separate days. In this context, the use of a single test for estimating aerobic capacity could be more practical.

Some indices of aerobic capacity, such as individual anaerobic threshold, ${ }^{3}$ anaerobic threshold, ${ }^{3,4}$ onset blood lactate accumulation, ${ }^{5}$ critical speed, ${ }^{6}$ and D-max, ${ }^{7}$ have been used as tools for estimating MLSS WORKLOAD. Most of these indices are based on lactate response to incremental step tests, which provide an exponential curve of blood lactate concentration-[La]-versus work rate. ${ }^{2,3}$ The onset of blood lactate accumulation has shown good validity in predicting MLSS WORKLOAD $_{\text {in different exercise }}$

Oliveira, Denadai, and Greco are with the Human Performance Laboratory, Sao Paulo State University, Rio Claro, SP, Brazil. Caputo and Lucas are with the Human Performance Research Group, Santa Catarina State University, Florianópolis, SC, Brazil. modes. ${ }^{2,4}$ On the other hand, some authors have argued against the use of a fixed [La] value because there is large individual variation in lactate's response to exercise. ${ }^{8}$

To overcome this difficulty, individualized methods have been proposed, such as individual anaerobic threshold $^{9}$ and D-max. ${ }^{10}$ Individual anaerobic threshold has been shown to overestimate MLSS $_{\text {WORKLOAD in rowing. }}{ }^{3}$ In contrast, Czuba et $\mathrm{al}^{7}$ showed that the anaerobic threshold calculated with the D-max method was not significantly different than and was highly correlated with $\operatorname{MLSS}_{\text {WORKLOAD }}(r=.97)$ during cycling. From the theoretical viewpoint, D-max is an arbitrary point on the regression curve that is used to characterize blood lactate kinetics in response to incremental exercise. The D-max method allows detection of a threshold point at all times by definition ${ }^{10}$ and has presented high test-retest reliability. ${ }^{11}$ Regardless of the method used, no studies have compared the physiological indices obtained during the incremental step test with the speed corresponding to MLSS in swimming ( $\left.\mathrm{S}_{\mathrm{MLSS}}\right)$. Therefore, the relationship between blood lactate response to incremental exercise (ie, a large increase in [La]) and MLSS, as well as the possibility of estimating $S_{M L S S}$, still needs to be explored in this modality.

The biomechanical skill required for swimming is of far greater importance for metabolic economy than 
those required for running and cycling. ${ }^{12}$ By using tests at different submaximal speeds, Wakayoshi et al ${ }^{13}$ confirmed the data reported by Keskinen and $\mathrm{Komi}^{14}$ that attributed to muscle fatigue the decrease in stroke length (SL) observed at speeds above onset blood lactate accumulation. Dekerle et al ${ }^{15}$ found no significant difference and a high correlation between $\mathrm{S}_{\mathrm{MLSS}}$ and the maximal speed above which SL tends to decrease during prolonged tests. These data suggest that metabolic changes detected by blood lactate are related to the changes observed in the stroke parameters. Thus, it can be hypothesized that changes in biomechanical stroke parameters during an incremental test can be used to estimate $S_{\text {MLSs }}$.

Therefore, the first purpose of this study was to evaluate the relationship between stroke parameters and blood lactate responses during an incremental test. To address this relationship, we compared and correlated the speeds determined through the D-max, that is, the swimming speeds associated with a large change in blood lactate and biomechanical stroke-parameter responses. The second purpose was to verify the validity of these physiological and biomechanical stroke parameters to estimate $S_{\text {MLSS }}$ by directly comparing the indices with $\mathrm{S}_{\mathrm{MLSS}}$. The third purpose was to relate these indices with 400-m freestyle swimming performance.

\section{Methods}

\section{Subjects}

Five male long-distance swimmers (specialists in 400-m, 800-m, 1500-m, and open-water swims) and 8 triathletes (age $23.8 \pm 9.5 \mathrm{y}$, height $1.76 \pm 0.1 \mathrm{~m}$, weight $71.3 \pm 9.8$ $\mathrm{kg}$ ) volunteered for and gave written informed consent to participate in the current study, which was approved by the university's ethics committee. The athletes had trained for at least 2 years ( $2 \mathrm{wk}$ before testing they were training $4.2 \pm 1$ sessions/wk with a volume of $18.8 \pm 5.9$ $\mathrm{km} / \mathrm{wk})$ and were competing in several regional- and national-level meets (400-m performance equal to 307.69 s, $69.3 \% \pm 3.9 \%$ of the world record). The participants were instructed to refrain from intense training sessions at least 24 hours before the experimental sessions. They were directed to report to the swimming pool in a rested state and to refrain from using caffeine, drugs, and alcohol for 24 hours before testing.

\section{Study Design}

The subjects first carried out a 400-m performance to determine their maximal aerobic speed $\left(\mathrm{S}_{400}\right)$. The other tests were then undertaken on separate days in a randomized order: a $7 \times 200-\mathrm{m}$ incremental test to assess [La] and biomechanical stroke parameters and several 30-minute submaximal constant-speed tests set at intensities ranging from $85 \%$ to $95 \%$ of the $\mathrm{S}_{400}$ in order to determine MLSS. ${ }^{15}$ Each test was preceded by a standard warm-up and started with a push start followed by a front-crawl stroke. Testing occurred at the same time of the day
$( \pm 2 \mathrm{~h}$ ) to minimize the effect of circadian variation on performance. $^{16,17}$

\section{Methodology}

All tests were performed in a $25-\mathrm{m}$ indoor swimming pool (water temperature $28^{\circ} \mathrm{C}$ ). During all the tests except the $400-\mathrm{m}$, swimming speed was controlled using an MP3 player attached to the swimmer's goggles (Acqua Player, Mormaii, Garopaba, Brazil). A regular audible signal enabled the swimmer to maintain the target pace. All swimmers were instructed to keep their feet beyond the red marks traced every $5 \mathrm{~m}$ at the bottom of the pool. Earlobe capillary blood samples $(\sim 25 \mu \mathrm{L})$ were collected in capillary tubes and subsequently analyzed for [La] using an automated analyzer (YSI 2300, Yellow Springs, $\mathrm{OH})$. The swimmers were filmed during all tests using 1 camera above the water surface (Panasonic PVGS65, São Paulo, Brazil) operating at $60 \mathrm{~Hz}$; this enabled analysis of the biomechanical stroke parameters.

The $7 \times 200-\mathrm{m}$ incremental test consisted of 7 evenpaced swims graded from easy to maximal. The speed of the first $200-\mathrm{m}$ stage was set at $79 \%$ of the $S_{400}$ and was subsequently increased by $3 \%$. Swimmers were instructed to swim the last $200 \mathrm{~m}$ with maximal effort (the actual speed was $\left.100.1 \% \pm 1.6 \% \mathrm{~S}_{400}\right)$. The target time was provided before each swim, although the audible signals permitted the swimmers to pace themselves over each 200 -m stage. The time for each $200-\mathrm{m}$ stage was manually recorded. All stages were followed by a 30 -second rest period to enable acquisition of a blood sample immediately after each stage for [La] determination.

All subjects performed two to four 30-minute constant submaximal tests ( 1 test per day) with blood samples collected at the 10 th (by a 30 -s rest period) and the 30 th minute to determine MLSS and its corresponding speed $\left(\mathrm{S}_{\mathrm{MLSS}}\right)$. Based on the results of Dekerle et al, ${ }^{15}$ the first trial was performed at $88 \%$ of $\mathrm{S}_{400}$. If, during the first 30-minute constant submaximal test, a steady state or a decrease in lactate was observed, further subsequent tests with $2.5 \%$ higher speed were performed on separate days until no [La] steady state could be maintained. If the first 30-minute constant submaximal test resulted in a clearly identifiable increase of the [La] or could not be completed due to exhaustion, further constant tests were conducted with subsequently reduced speed $(2.5 \%)$. MLSS was defined as the highest [La] that increased by no more than $1 \mathrm{mmol} / \mathrm{L}$ between the 10 th and 30 th minutes of the test. ${ }^{2}$

Stroke rate (SR), SL, and stroke index (SI) were determined in all tests. The time required to complete 5 stroke cycles in the middle of each length $(25 \mathrm{~m})$ was used to calculate SR. SL was calculated by dividing the speed (25-m average speed) by SR. SI corresponded to the product of speed and SL. This method has been proven reliable and valid. ${ }^{18}$ All stroke-parameter measurements were averaged for the last $150 \mathrm{~m}$ of each stage throughout the incremental test.

Assuming the nonlinear response of the blood lactate and biomechanical stroke parameters during the 

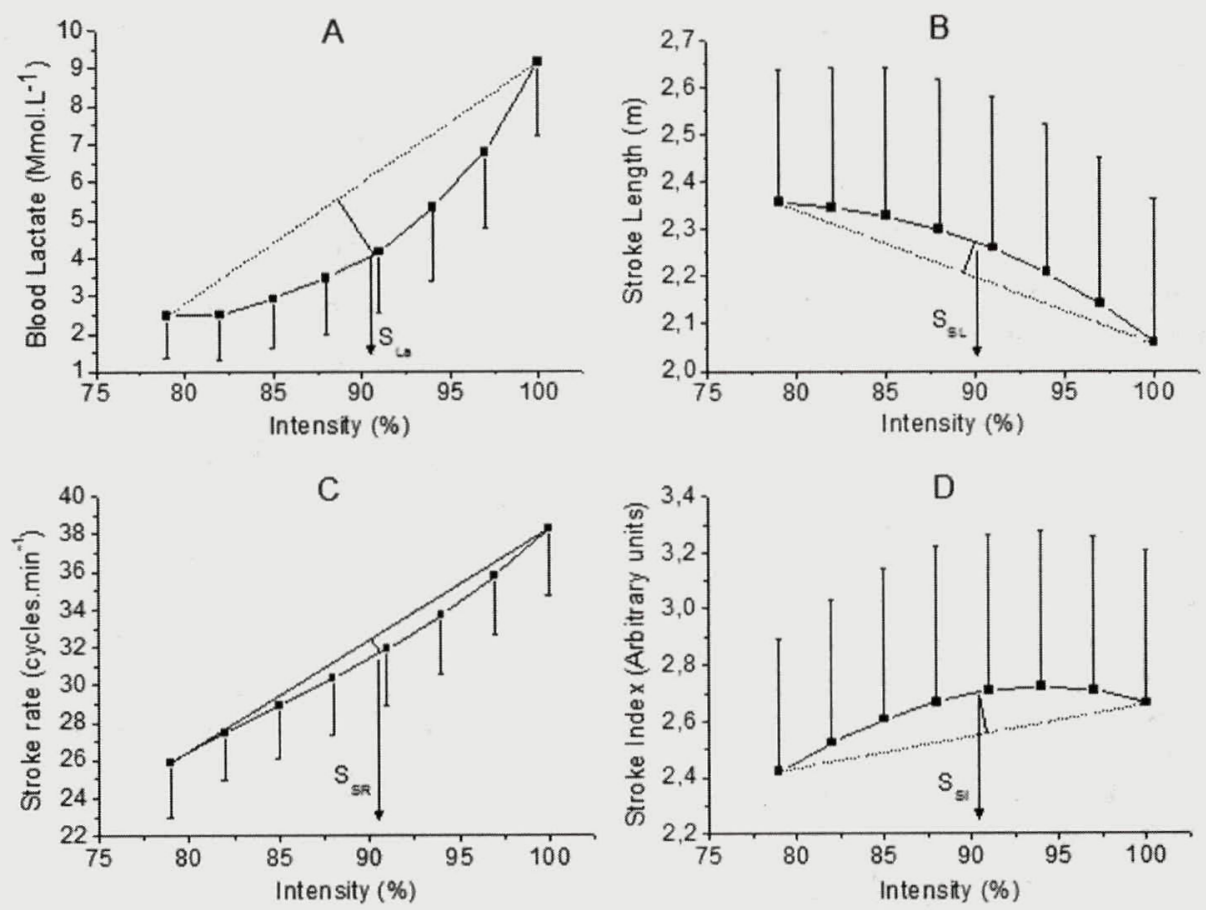

Figure 1 - (A) Blood-lactate, (B) stroke-length, (C) stroke-rate, and (D) stroke-index responses as a function of exercise intensity relative to maximum speed reached during the incremental test, mean $\pm \mathrm{SD} . \mathrm{S}_{\mathrm{LA}}, \mathrm{S}_{\mathrm{SL}}, \mathrm{S}_{\mathrm{SR}}$, and $\mathrm{S}_{\mathrm{SI}}$ demonstrate the relative speed at the D-max point for blood lactate, stroke length, stroke rate, and stroke index, respectively $(\mathrm{N}=13)$.

incremental test, we used the D-max method to identify a threshold for the blood lactate $\left(\mathrm{S}_{\mathrm{LA}}\right), \mathrm{SR}\left(\mathrm{S}_{\mathrm{SR}}\right), \mathrm{SL}$ $\left(\mathrm{S}_{\mathrm{SL}}\right)$, and $\mathrm{SI}\left(\mathrm{S}_{\mathrm{SI}}\right)$ responses (Figure 1). Using the D-max method, third-order curvilinear regression was calculated from the dependent values versus speed in the incremental test. Two end points of the curve were connected by a straight line, and the most distant point of the curve from the line was considered D-max. The point yielding the maximal distance (D-max) derived from the computation was taken as the threshold.

\section{Statistical Analysis}

The values are expressed as mean \pm SD. The normality of distribution was checked by the Shapiro-Wilk test. One-way analysis of variance was used to compare the speeds corresponding to the different methods, with the use of a Tukey post hoc test where appropriate. Pearson product-moment correlation coefficients were used to assess the significance of the relationships between all variables. In addition, the typical error of estimate (TEE) was calculated as described by Hopkins. ${ }^{19}$ Significance was accepted when $P<.05$.

\section{Results}

Table 1 presents the means \pm SDs of the variables obtained during the incremental tests. The maximum speed $\left(\mathrm{S}_{\text {MAX }}\right)$ obtained during the incremental test (1.39 $\pm 0.6 \mathrm{~m} / \mathrm{s})$ was similar to $S_{400}(1.34 \pm 0.08 \mathrm{~m} / \mathrm{s})$. Figure
1 depicts the mean \pm SD of blood lactate, SL, SR, and SI responses as a function of exercise intensity relative to maximum speed reached during the incremental test. There were no significant differences between $\mathrm{S}_{\mathrm{LA}}, \mathrm{S}_{\mathrm{SI}}$, $\mathrm{S}_{\mathrm{SR}}, \mathrm{S}_{\mathrm{SL}}$, and $\mathrm{S}_{\mathrm{MLSS}}$.

Table 2 shows the correlation matrix between the variables $\mathrm{S}_{\mathrm{MLSS}}, \mathrm{S}_{\mathrm{LA}}, \mathrm{S}_{\mathrm{SI}}, \mathrm{S}_{\mathrm{SR}}, \mathrm{S}_{\mathrm{SL}}, \mathrm{S}_{400}$, and $\mathrm{S}_{\mathrm{MAX}}$. All variables were significantly correlated $(P<.05)$. The TEE suggests good validity of $\mathrm{S}_{\mathrm{LA}}(3.2 \%), \mathrm{S}_{\mathrm{SI}}$ $(3.7 \%), \mathrm{S}_{\mathrm{SR}}(4.1 \%)$, and $\mathrm{S}_{\mathrm{SL}}(4.7 \%)$ for estimating SMLSS.

The mean \pm SD of the SR, SL, and SI during MLSS were $31.5 \pm 2.0$ cycles $/ \mathrm{min}, 2.15 \pm 0.3 \mathrm{~m} /$ cycle, and 2.43 \pm 0.5 arbitrary units, respectively.

\section{Discussion}

The main finding of the current study was that swimming speed corresponding to D-max using both [La] and biomechanical stroke-parameter (SR, SL, SI) responses obtained from the incremental tests demonstrated good validity for predicting aerobic capacity and swimming performance $(400-\mathrm{m})$. To our knowledge, this is the first study to use the D-max method to determine the thresholds through biomechanical stroke parameters in a swimming incremental test. This method was previously used during incremental tests to determine lactate threshold ${ }^{7,11}$ and heart-rate deflection points, ${ }^{20}$ primarily during cycling and running exercises. Furthermore, comparisons between $\mathrm{S}_{\mathrm{MLSS}}$ and different parameters (physiological 
Table 1 Absolute Speed (S), Blood Lactate Concentration ([La]), Speed Relative to the Maximum Speed Obtained During an Incremental Test ( $S_{\text {MAX }}$ ), and Speed Relative to Mean 400-m Speed $\left(S_{400}\right)$ for the Variables Determined During Incremental and Constant-Load Tests, Mean \pm SD

\begin{tabular}{lcccc}
\hline & $\mathbf{S}(\mathrm{m} / \mathrm{s})$ & {$[\mathrm{La}](\mathrm{mM})$} & $\mathrm{S}_{\mathrm{MAX}}(\%)$ & $\mathrm{S}_{400}(\%)$ \\
\hline $\mathrm{S}_{\mathrm{La}}$ & $1.18 \pm 0.08$ & $3.9 \pm 1.5$ & $90.5 \pm 3.21$ & $90.6 \pm 2.64$ \\
$\mathrm{~S}_{\mathrm{SI}}$ & $1.18 \pm 0.08$ & $4.05 \pm 1.53$ & $90.2 \pm 2.5$ & $90.3 \pm 3.2$ \\
$\mathrm{~S}_{\mathrm{SR}}$ & $1.17 \pm 0.1$ & $3.97 \pm 1.62$ & $89.9 \pm 4.3$ & $90.0 \pm 3.9$ \\
$\mathrm{~S}_{\mathrm{SL}}$ & $1.16 \pm 0.09$ & $3.73 \pm 1.56$ & $89.1 \pm 4.5$ & $89.2 \pm 4.2$ \\
$\mathrm{~S}_{\mathrm{MLSS}}$ & $1.13 \pm 0.08$ & $4.4 \pm 1.5$ & $87 \pm 2.0$ & $88 \pm 6.3$ \\
\hline
\end{tabular}

Abbreviations: $\mathrm{S}_{\mathrm{La}}, \mathrm{S}_{\mathrm{SL}}, \mathrm{S}_{\mathrm{SR}}$, and $\mathrm{S}_{\mathrm{SI}}$, the speed at the D-max point for the blood lactate, stroke-length, stroke-rate, and stroke-index responses, respectively; $\mathrm{S}_{\mathrm{MLSS}}$, the speed corresponding to maximal lactate steady state. Values were not significantly different $(P>.05) ; \mathrm{N}=13$.

Table 2 Correlation Matrix Between the Selected Variables

\begin{tabular}{l|ccccccc}
\hline & $\mathbf{S}_{\text {MLSS }}$ & $\mathbf{S}_{\text {La }}$ & $\mathbf{S}_{\mathbf{S L}}$ & $\mathbf{S}_{\mathbf{S R}}$ & $\mathbf{S}_{\mathbf{S I}}$ & $\mathbf{S}_{\mathbf{4 0 0}}$ & $\mathbf{S}_{\mathbf{M A X}}$ \\
\hline $\mathrm{S}_{\mathbf{M L S S}}$ & 1 & .91 & .80 & .85 & .89 & .93 & .95 \\
$\mathrm{~S}_{\text {La }}$ & .91 & 1 & .75 & .92 & .85 & .95 & .90 \\
$\mathrm{~S}_{\mathrm{SL}}$ & .80 & .75 & 1 & .86 & .81 & .73 & .70 \\
$\mathrm{~S}_{\mathrm{SR}}$ & .85 & .92 & .86 & 1 & .90 & .87 & .82 \\
$\mathrm{~S}_{\mathrm{SI}}$ & .89 & .85 & .81 & .90 & 1 & .86 & .92 \\
$\mathrm{~S}_{\mathbf{4 0 0}}$ & .93 & .95 & .73 & .87 & .86 & 1 & .92 \\
$\mathbf{S}_{\text {MAX }}$ & .95 & .90 & .70 & .82 & .92 & .92 & 1 \\
\hline
\end{tabular}

Abbreviations: $S_{\mathrm{MLSS}}$, the speed corresponding to maximal lactate steady state; $\mathrm{S}_{\mathrm{La}}, \mathrm{S}_{\mathrm{SL}}, \mathrm{S}_{\mathrm{SR}}$, and $\mathrm{S}_{\mathrm{SI}}$, the speed at the D-max point for the blood lactate, stroke-length, stroke-rate, and stroke-index responses, respectively. All correlations are significant $(P<.05) ; \mathrm{N}=13$.

and biomechanical) obtained from a single incremental test in swimming are scarce.

In the current study, the D-max method was used to overcome the shortcomings of visual or predetermined fixed-value threshold determination, such as subjectivity and lack of individuality. Another advantage of the D-max method is that the point considered the threshold can always be detected by definition. ${ }^{10}$ These aspects are particularly important in biomechanical analyses because the stroke parameters (SL, SR, and SI) may not present similar responses within or between subjects. ${ }^{14,21,22}$ In our study, the D-max method seems to be appropriate for determining the selected indices because the $\mathrm{S}_{\mathrm{SI}}$, $\mathrm{S}_{\mathrm{SR}}, \mathrm{S}_{\mathrm{SL}}, \mathrm{S}_{\mathrm{LA}}$, and $\mathrm{S}_{\mathrm{MLSS}}$ did not differ significantly and were strongly correlated (Table 2 ). Specifically for $S_{L A}$, our results are consistent with those of Czuba et al, ${ }^{7}$ who found no significant differences and strong correlation ( $r=.97$ ) between the lactate-threshold intensities determined using the D-max method and MLSS $_{\text {WORKLOAD }}$ in cycling.

In swimming, much research has associated changes in technical variables with changes observed in metabolic variables. ${ }^{13,15,23}$ This temporal relationship has been shown by studies in which stroke-parameter changes during incremental step testing were concomitant with changes in blood lactate response. ${ }^{13,24,25}$ Although earlier studies $^{13,14,23}$ only observed these aspects on average, that is, for a whole population, our data also confirm an association between blood lactate response and stroke parameters. Thus, the lack of a significant difference, as well as the high correlation found between D-max speeds (individualized physiological and biomechanical thresholds) and $\mathrm{S}_{\mathrm{MLSS}}$, suggests a cause-effect relationship between fatigue (blood lactate accumulation) and stroke technique.

Along with these other studies, Dekerle et al ${ }^{15}$ showed that SL tends to progressively decrease in exercises performed above $\mathrm{S}_{\mathrm{MLSS}}$. Barden and Kell ${ }^{26}$ showed that above the critical speed, SR and SL were significantly higher and lower, respectively, than below critical speed and that these changes occurred in an abrupt and nonlinear manner. Overall, these data suggest that the aerobiccapacity indices (MLSS, critical speed, $\mathrm{S}_{\mathrm{SI}}, \mathrm{S}_{\mathrm{SR}}, \mathrm{S}_{\mathrm{SL}}$, and $S_{\mathrm{LA}}$ ) represent a transition point between the 2 different sets of stroke-parameter responses. However, Psycharakis et $\mathrm{al}^{27}$ found that kinematic changes in stroke parameters during the incremental step test were higher during the early stages (when the [La] values were 1-3.5 mM) and concluded that there is no association between any modified or break point in the stroke parameters and the speed associated with onset blood lactate accumulation (4 mM). Nevertheless, those authors analyzed the relationship between SL and [La] as an average, not individually. In addition, the incremental protocol Psycharakis et $\mathrm{al}^{27}$ used had a long recovery period between stages $(\sim 150$ s). Because [La] is work-rate- and time-dependent, ${ }^{2,5}$ short efforts interspersed with equal recovery periods may affect the [La] kinetics during incremental tests (mainly [La] removal after each stage) compared with studies that suggest the fixed 4-mM value as an MLSS estimate. ${ }^{2}$ Furthermore, the stroke changes observed by Psycharakis et $\mathrm{al}^{27}$ for female freestyle swimmers were different than those observed for the male swimmers; 
that is, no or slight decrease in SL was observed with increasing speed. These data support the relevance of using an individual method (eg, D-max) to determine the relationship between SL and [La], especially when the incremental protocols have different characteristics such as step duration and recovery time.

This discussion leaves a wide margin in which the boundary between the heavy- and severe-intensity domains can be located. Particularly in swimming, the relationship between speed and energetic cost is not linear ${ }^{28}$; therefore, slight variations in speed represent large variations in metabolic cost and cardiovascular responses during exercise. Despite the low TEE values $\left(\mathrm{S}_{\mathrm{SI}} 3.7 \%, \mathrm{~S}_{\mathrm{SR}} 4.1 \%, \mathrm{~S}_{\mathrm{SL}} 4.7 \%\right.$, and $\left.\mathrm{S}_{\mathrm{La}} 3.2 \%\right)$ found in the variables used to estimate $S_{\mathrm{MLSS}}$, all TEE values were greater than the speed increment $(2.5 \%)$ used between constant-load tests to determine $\mathrm{S}_{\mathrm{MLSs}}$. Thus, increments as low as $2.5 \%$ in swimming speed may induce increases in [La] over time and represent different exerciseintensity domains. Corroborating this finding, Dekerle et $\mathrm{al}^{29}$ showed that the time to exhaustion at $5 \%$ below the critical speed $(48.9 \pm 14.1 \mathrm{~min})$ was twice that in critical speed $(24.3 \pm 7.7 \mathrm{~min})$. Moreover, in another study, 6 of 11 subjects were not able to complete 30 minutes at a speed 5\% above the $\mathrm{S}_{\mathrm{MLSs}} .^{15}$ Despite these aspects, all indirect variables were highly correlated with $\mathrm{S}_{\mathrm{MLSS}}$ and $S_{400}$, demonstrating good validity for their use in predicting aerobic capacity and aerobic performance during swimming. Although it could be advantageous to use a single incremental step test to indirectly determine aerobic capacity, special attention should be given if these indices will be used for training prescription, especially for highly trained athletes.

In the current study, reproducibility of the selected variables was not checked; this could represent an important limitation. Zhou and Weston ${ }^{11}$ demonstrated high test-retest reliability of exercise intensity at the D-max point on the blood lactate response during cycling. In swimming, Anderson et $\mathrm{al}^{30}$ found low typical error values in speed $(0.8 \%)$, SR $(3 \%)$, and SL $(2.9 \%)$ at the intensity of onset blood lactate accumulation obtained during the incremental step test, demonstrating good reliability of these parameters. Furthermore, that same group of authors ${ }^{25}$ and others ${ }^{26}$ monitoring seasonal and long-term changes in incremental testing in elite swimmers have highlighted the utility of these measures for monitoring training-induced improvements in endurance fitness. Thus, these data suggest that the indices determined in the current study have good reproducibility and sensitivity to the effects of aerobic training.

\section{Conclusion}

The lack of a significant difference and the strong relationship between swimming speed at the D-max point on the blood lactate and biomechanical stroke-parameter responses suggests that, in addition to being simple and noninvasive measures, these technical variables have the same practical usefulness as $[\mathrm{La}]$ for determining aerobic capacity and performance. However, despite low TEE values, the physiological and biomechanical indices may not represent [La] equilibrium over time. Therefore, we recommend that $\mathrm{S}_{\mathrm{MLSS}}$ be determined directly whenever precision is required. Moreover, additional studies using swimmers of higher experience level or a longitudinal experimental design (ie, training effects) may provide further information regarding the validity of the stroke parameters to estimate aerobic capacity from a single incremental test.

\section{Practical Implications}

- A single test can be used to indirectly determine aerobic capacity and predict performance.

- Stroke-parameter thresholds are simply and noninvasively measured and provide useful information for training prescription and monitoring trained-induced improvements in endurance fitness.

- Given the importance of SL in propelling efficiency and swimming performance, it would be beneficial for swimmers to practice lengthening their stroke cycles during training and to try to resist decreases in SL as speed increases, that is, a right shift in the $\mathrm{SL}-$ speed relationship- $\mathrm{S}_{\mathrm{SL}}$. This could enable swimmers to attain higher speeds with the same SL values increasing the $S_{S L}$ as a training-induced adjustment.

- Special attention should be given if these indirect indices will be used for training prescription, because they may not represent the speed at which [La] remains stable over time.

\section{Acknowledgments}

This research was supported by grants from Fundação de Amparo à Pesquisa do Estado de São Paulo and Conselho Nacional de Desenvolvimento Científico e Tecnológico.

\section{References}

1. Beneke R, Von Duvillard SP. Determination of maximal lactate steady state response in selected sports events. Med Sci Sports Exerc. 1996;28(2):241-246. PubMed doi:10.1097/00005768-199602000-00013

2. Heck H, Mader A, Hess G, et al. Justification of the 4-mmol/l lactate threshold. Int J Sports Med. 1985;6(3):117-130. PubMed doi:10.1055/s-2008-1025824

3. Beneke R. Anaerobic threshold, individual anaerobic threshold, and maximal lactate steady state in rowing. Med Sci Sports Exerc. 1995;27(6):863-867. PubMed

4. Denadai BS, Figueira TR, Favaro OR, et al. Effect of the aerobic capacity on the validity of the anaerobic threshold for determination of the maximal lactate steady state in cycling. Braz J Med Biol Res. 2004;37(10):1551-1556. PubMed doi:10.1590/S0100-879X2004001000015

5. Figueira TR, Caputo F, Pelarigo JG, et al. Influence of exercise mode and maximal lactate-steady-state con- 
centration on the validity of OBLA to predict maximal lactate-steady-state in active individuals. J Sci Med Sport. 2008;11(3):280-286. PubMed doi:10.1016/j. jsams.2007.02.016

6. Wakayoshi K, Yoshida T, Udo M, et al. Does critical swimming velocity represent exercise intensity at maximal lactate steady state? Eur J Appl Physiol Occup Physiol. 1993;66(1):90-95. PubMed doi:10.1007/BF00863406

7. Czuba M, Zajac A, Cholewa J. Lactate threshold (D-max method) and maximal lactate steady state in cyclists. J Hum Kinet. 2009;21:49-56. doi:10.2478/v10078-09-0006-5

8. Van Schuylenbergh R, Vanden Eynde B, Hespel P. Correlations between lactate and ventilatory thresholds and the maximal lactate steady state in elite cyclists. Int J Sports Med. 2004;25(6):403-408. PubMed doi:10.1055/s-2004-819942

9. Coen B, Urhausen A, Kindermann W. Individual anaerobic threshold: methodological aspects of its assessment in running. Int J Sports Med. 2001;22(1):8-16. PubMed doi:10.1055/s-2001-11332

10. Cheng B, Kuipers H, Snyder AC, et al. A new approach for the determination of ventilatory and lactate thresholds. Int J Sports Med. 1992;13(7):518-522. PubMed doi:10.1055/s-2007-1021309

11. Zhou S, Weston SB. Reliability of using the D-max method to define physiological responses to incremental exercise testing. Physiol Meas. 1997;18(2):145-154. PubMed doi:10.1088/0967-3334/18/2/005

12. Dekerle J, Sidney M, Hespel JM, et al. Validity and reliability of critical speed, critical stroke rate, and anaerobic capacity in relation to front crawl swimming performances. Int J Sports Med. 2002;23(2):93-98. PubMed doi:10.1055/s-2002-20125

13. Wakayoshi K, D’Acquisto LJ, Cappaert JM, Troup JP. Relationship between oxygen uptake, stroke rate and swimming velocity in competitive swimming. Int J Sports Med. 1995;16(1):19-23. PubMed doi:10.1055/s-2007-972957

14. Keskinen KL, Komi PV. The stroking characteristics of front crawl swimming during exercise. J Appl Biomech. 1993;9:219-226.

15. Dekerle J, Nesi X, Lefevre T, et al. Stroking parameters in front crawl swimming and maximal lactate steady state speed. Int J Sports Med. 2005;26(1):53-58. PubMed doi:10.1055/s-2004-817854

16. Atkinson G, Reilly T. Circadian variation in sports performance. Sports Med. 1996;21(4):292-312. PubMed doi:10.2165/00007256-199621040-00005

17. Bessot N, Nicolas A, Moussay S, et al. The effect of pedal rate and time of day on the time to exhaustion from high- intensity exercise. Chronobiol Int. 2006;23(5):1009-1024. PubMed doi:10.1080/07420520600920726

18. Chollet D, Pelayo P. Effect of different methodologies in calculating stroke length in swimming. J Hum Mov Stud. 1999;36:127-136.

19. Hopkins WG. Measures of reliability in sports medicine and science. Sports Med. 2000;30(1):1-15. PubMed doi:10.2165/00007256-200030010-00001

20. Bodner ME, Rhodes EC. A review of the concept of the heart rate deflection point. Sports Med. 2000;30(1):31-46. PubMed doi:10.2165/00007256-200030010-00004

21. Toussaint HM. Differences in propelling efficiency between competitive and triathlon swimmers. Med Sci Sports Exerc. 1990;22(3):409-415. PubMed

22. Capelli C, Zamparo P, Cigalotto A, et al. Bioenergetics and biomechanics of front crawl swimming. J Appl Physiol. 1995;78(2):674-679. PubMed

23. Craig AB, Pendergast DR. Relationships of stroke rate, distance per stroke, and velocity in competitive swimming. Med Sci Sports. 1979;11(3):278-283. PubMed doi:10.1249/00005768-197901130-00011

24. Pyne DB, Lee H, Swanwick KM. Monitoring the lactate threshold in world-ranked swimmers. Med Sci Sports Exerc. 2001;33(2):291-297. PubMed

25. Anderson M, Hopkins W, Roberts A, et al. Monitoring seasonal and long-term changes in test performance in elite swimmers. Eur J Sport Sci. 2006;6(3):145-154. doi:10.1080/17461390500529574

26. Barden JM, Kell RT. Relationships between stroke parameters and critical swimming speed in a sprint interval training set. J Sports Sci. 2009;27(3):227-235. PubMed doi: $10.1080 / 02640410802475205$

27. Psycharakis SG, Cooke CB, Paradisis GP, et al. Analysis of selected kinematic and physiological performance determinants during incremental testing in elite swimmers. J Strength Cond Res. 2008;22(3):951-957. PubMed doi:10.1519/JSC.0b013e31816a6364

28. Capelli C, Pendergast DR, Termin B. Energetics of swimming at maximal speeds in humans. Eur J Appl Physiol Occup Physiol. 1998;78(5):385-393. PubMed doi:10.1007/s004210050435

29. Dekerle J, Brickley G, Alberty M, et al. Characterising the slope of the distance-time relationship in swimming. J Sci Med Sport. 2010;13(3):365-370. PubMed doi:10.1016/j. jsams.2009.05.007

30. Anderson M, Hopkins W, Roberts A, et al. Ability of test measures to predict competitive performance in elite swimmers. J Sports Sci. 2008;26(2):123-130. PubMed doi:10.1080/02640410701348669 
Copyright of International Journal of Sports Physiology \& Performance is the property of Human Kinetics Publishers, Inc. and its content may not be copied or emailed to multiple sites or posted to a listserv without the copyright holder's express written permission. However, users may print, download, or email articles for individual use. 